\title{
Correction to: Case report: acute clinical presentation and neonatal management of primary hyperparathyroidism due to a novel CaSR mutation
}

Manuela Capozza ${ }^{1,7^{*}}$, Iolanda Chinellato ${ }^{2}$, Vito Guarnieri ${ }^{3}$, Natascia Di lorgi $i^{4}$, Maria Accadia ${ }^{3}$, Cristina Traggiai ${ }^{5}$, Girolamo Mattiolii, Antonio Di Mauro ${ }^{1}$ and Nicola Laforgia ${ }^{1}$

\section{Correction to: BMC Pediatrics (2018) 18:340}

https://doi.org/10.1186/s12887-018-1319-0

In the published article [1], an error has been noticed in the author group section.

Namely, one of the author names is captured incorrectly: Natascia Di lorgi (using lowercase letter L in family name) should be spelled as Natascia Di Iorgi (using uppercase letter I).

\begin{abstract}
Author details
${ }^{1}$ Neonatology and Neonatal Intensive Care Unit, Department of Biomedical Science ad Human Oncology, University of Bari "Aldo Moro", Bari, Italy. ${ }^{2}$ S.C.Pediatria, P.O.C. SS. Annunziata Hospital, Taranto, Italy. ${ }^{3}$ Medical Genetics, IRCCS Casa Sollievo della Sofferenza Hospital, San Giovanni Rotondo, Foggia, Italy. ${ }^{4}$ Department of Pediatrics, Endocrine, Diabetes and Metabolic Unit, Istituto Giannina Gaslini, University of Genova, Genoa, Italy. ${ }^{5}$ Neonatology and Neonatal Intensive Care Unit, Istituto Giannina Gaslini, Genoa, Italy. ${ }^{6}$ Pediatric Surgery Unit, Istituto Giannina Gaslini, University of Genoa, Genoa, Italy. ${ }^{7}$ Policlinico Hospital, Piazza Giulio Cesare n. 11, 70124 Bari, Italy.
\end{abstract}

Published online: 27 November 2019

\section{Reference}

1. Capozza M, Chinellato I, Guarnieri V, Di lorgi N, Accadia M, Traggiai C, Mattioli G, Di Mauro A, Laforgia N. Case report: acute clinical presentation and neonatal management of primary hyperparathyroidism due to a novel CaSR mutation. BMC Pediatrics. 2018;18:340. https://doi.org/10.1186/s12887018-1319-0.

Full list of author information is available at the end of the article

(c) The Author(s). 2019 Open Access This article is distributed under the terms of the Creative Commons Attribution 4.0 International License (http://creativecommons.org/licenses/by/4.0/), which permits unrestricted use, distribution, and reproduction in any medium, provided you give appropriate credit to the original author(s) and the source, provide a link to the Creative Commons license, and indicate if changes were made. The Creative Commons Public Domain Dedication waiver (http://creativecommons.org/publicdomain/zero/1.0/) applies to the data made available in this article, unless otherwise stated. 